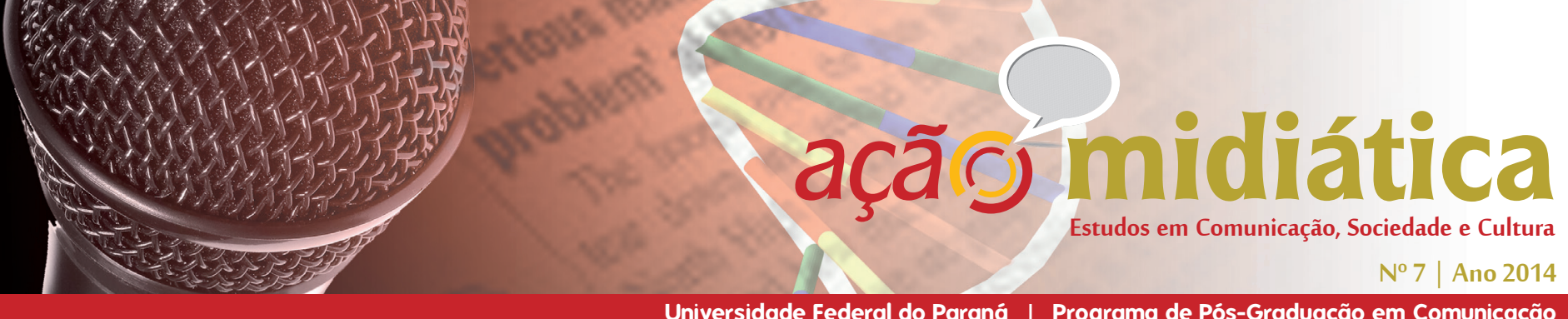

Universidade Federal do Paraná | Programa de Pós-Graduacãa em Comunicação

\title{
Comunicação Científica Além da Ciência ${ }^{1}$
}

\author{
Scientific Communication and the Science
}

Comunicación Científica y la Ciencia

\author{
Maria das Graças TARGINO2 \\ Názia Holanda TORRES 3
}

\begin{abstract}
Resumo
Objetiva-se discutir a comunicação científica além da ciência, ou seja, a importância do fluxo informacional que extrapola os limites da comunidade científica e chega às coletividades. A comunicação científica fundamenta-se na informação científica, responsável pelo conhecimento científico, o qual representa acréscimo ao status quo das áreas de conhecimento. A pesquisa científica está no alicerce da comunicação científica. Esta extrapola o ciclo restrito de fluxo informacional intramuros (comunidade científica) e, graças à divulgação científica, alcança a população, transformando-a em alfabetizada cientificamente. Ciência e tecnologia determinam a evolução da humanidade, o que requer dos cidadãos habilidades para desvendarem o universo da ciência, pois a inacessibilidade aos novos conhecimentos cerceia a prática cidadã.
\end{abstract}

Palavras-chave: Comunicação científica; Divulgação científica; Alfabetização científica.

\begin{abstract}
It aims to discuss the scientific communication over the science itself. It shows the value of the informational flow what goes along the scientific community's bounders and arrives at the center of the collectivities. The scientific information puts itself as the first element of the scientific communication because it is the main responsible for the scientific knowledge, which represents itself the advance to the status quo of the knowledge. The scientific information circles within the scientific community and because of the importance of the scientific divulgation soon it causes significant chances among the populations. So, people go to be alphabetized scientifically. Finally, science and technology are the principal factors for the evolution of the
\end{abstract}

1 Trabalho apresentado à sétima edição da Revista Ação Midiática - Estudos em Comunicação, Sociedade e Cultura, publicação ligada ao Programa de Pós-Graduação em Comunicação, da Universidade Federal do Paraná.

2 Doutora em Ciência da Informação pela Universidade de Brasília e jornalista, finalizou seus estudos em nível de pós-doutorado junto ao Instituto Interuniversitario de Iberoamérica da Universidad de Salamanca, e Máster Internacional en Comunicación y Educación, Universidad Autónoma de Barcelona (Espanha). Atuou como pesquisadora junto ao referido Instituto / USAL, de março de 2010 a julho de 2011. Ao longo das décadas, escreveu centenas de artigos técnico-científicos, capítulos de livros e livros nas áreas de ciência de informação e comunicação, enveredando pela literatura. Após manter vinculação com a Universidade Federal do Piauí por 30 anos, atua como Coordenadora Local do Plano Nacional de Formação de Professores da Educação Básica / Universidade Federal do Piauí (PARFOR/UFPI) e como docente do quadro permanente do Programa de Pós-Graduação em Ciência da Informação da Universidade Federal da Paraíba (UFPB). Dentre atividades atuais, também é membro da Comissão Editorial (permanente ou ad hoc) de diferentes periódicos nacionais e internacionais. Escreve, a cada semana, coluna de opinião no jornal diário O Dia, Teresina - PI. Dentre os prêmios conquistados está o Prêmio Nacional Luiz Beltrão de Comunicação.E-mail: gracatargino@hotmail.com

3 Mestre em Ciência da informação pela Universidade Federal da Paraíba, João Pessoa - PB, Brasil. Graduada em Biblioteconomia pela Universidade Federal do Ceará, Fortaleza - CE, Brasil. Bibliotecária do Instituto Federal SERTÃO - PE, Campus Ouricuri, Ouricuri - Pernambuco, Brasil.E-mail: nazia.holanda@yahoo.com.br 


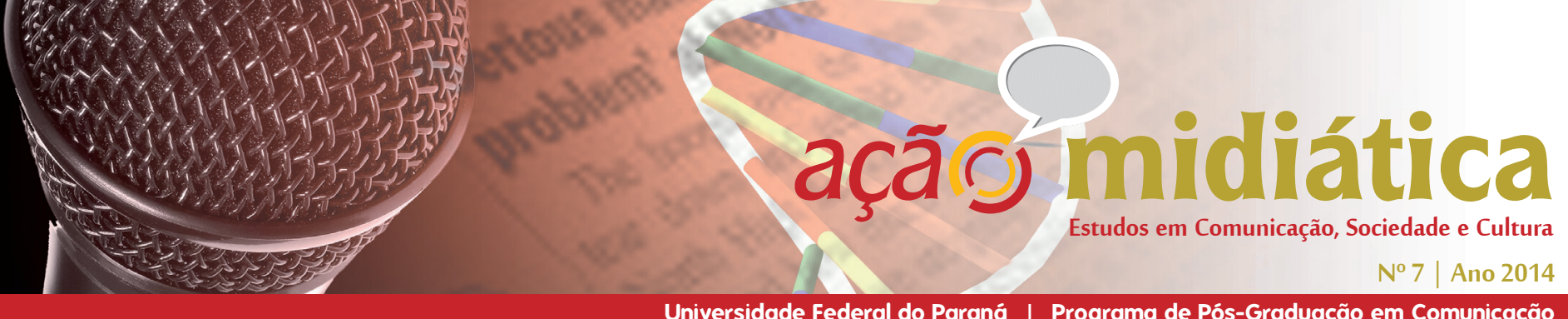

humanity, what leads to conceptual changes which require some abilities of the citizens in order to understand the scientific universe, which, however, must respect the citizenship.

Keywords: Scientific communication; Scientific divulgation; Scientific alphabetization.

\section{Resumen}

El objetivo es discutir la comunicación científica más ahí de la ciencia, o sea, la importancia del flujo informacional que ultrapasa los límites de la comunidad científica y llega hasta las colectividades. La comunicación científica está basada en la información científica, responsable por el conocimiento científico, lo cual representa uno avanzo al status quo del conocimiento. La investigación científica está en la base de la comunicación científica en su totalidad. Esta extrapola el ciclo restricto del flujo informacional en el interior de la comunidad científica y gracias a la divulgación científica llega hasta la populación que pasa a ser alfabetizada científicamente. Ciencia y tecnología determinan la evolución de la humanidad. Eso requiere de los ciudadanos algunas habilidades con el fin de descubrir el universo de la ciencia, una vez que la inaccesibilidad a los nuevos conocimientos impide la práctica ciudadana.

Palabras clave: Comunicación científica; Divulgación científica; Alfabetización científica.

\section{Palavras introdutórias}

Nos dias atuais, o tema comunicação científica está por toda parte. Há eventos acadêmicos e científicos voltados à sua discussão. Veiculam-se artigos impressos e eletrônicos; matérias jornalísticas; livros individuais e coletâneas; dissertações e teses; e assim quase infinitamente. É como se fora algo novo e/ou inovador. Algum elemento estreante na vida dos que se dedicam a analisar o avanço de povos e nações. No entanto, a comunicação científica está no alicerce do desenvolvimento da espécie humana desde os primórdios, no momento em que, recorrendo a recursos os mais primitivos possíveis, o homem faz circular as mudanças por ele alcançadas, sempre em busca de uma vida melhor, seja no âmbito das comunidades tribais e/ou nômades, seja no contexto das sociedades fixas e evoluídas. Obviamente, trata-se de visão demasiadamente ampla (mas não equivocada) de que o desenvolvimento contínuo da humanidade ocorre graças à circulação de informações de naturezas distintas.

É esse fluxo informacional que faz as inovações científicas e tecnológicas girarem com maior celeridade, mais adiante, graças ao advento da imprensa e, sobretudo, à sua expansão, por conta da heterogeneidade crescente de materiais e suportes até conquistar a vertiginosa fluidez das redes eletrônicas de informação e de comunicação, ênfase para a internet. Tudo isso permite inferir que, na atualidade e em qualquer época da história, a comunicação científica é indispensável ao progresso dos países. É só imaginar o que teria acontecido se as grandes 
invenções da humanidade não tivessem sido comunicadas, compartilhadas, disseminadas e transformadas... E quando se fala em "grandes invenções", há referência implícita a elementos que, hoje, parecem peças arcaicas ou cuja presença é demasiadamente óbvia para ser rememorada pelo ser humano em seu cotidiano. É o caso, por exemplo, de ferramentas básicas, como martelos, facas e similares, introduzidas ainda no período paleolítico. Se, hoje, perdem sua importância quando em confronto com invenções subsequentes e cheias de glamour, esses dispositivos têm seu lugar de destaque como elementos definitivos para assegurar a sobrevivência da espécie, favorecendo, à época, a prática da caça, da pesca, da produção artesanal de vestimentas, do corte de árvores, etc.

Assim, além de "venerar" os computadores em sua imensa diversidade, os satélites de comunicação, os teletextos, a vídeo-instrução baseada em computador, os videotextos, os audiotextos, os electronic books (e-books), os hipertextos, o blu-ray disc ou BD, o digital versatile disc (o popular DVD), a telefonia celular e suas surpreendentes potencialidades; os diários eletrônicos e digitais, a televisão digital, os terminais de TV por cabo ou paga ou por contrato ou, incluso, a TV interativa e a televisão de alta definição, e, também, a TV 3D, precisamos reverenciar o passado. Eis a única "fórmula" para reconhecer a importância da comunicação científica. Retomar o passado e valorizar o lugar conquistado - cada qual à sua época - por outros elementos, como a roda, o fogo/a pólvora, o vidro, os sistemas de esgoto, a bússola magnética, os óculos com sua imensa magia, relógios e telescópios, microfilmes e até o compact disc read-only memory (CD-ROM). O que dizer das baterias, da lâmpada, do plástico, do telefone (os velhos telefones fixos), da TV em preto e branco, da comunicação sem fio, dos radares e dos cartões de crédito, hoje, integrantes do dia a dia do homem comum? E a fotografia digital, em si mesma, "filha legítima" da saudosa fotografia analógica?

Vê-se, pois, que há evolução permanente das descobertas científicas. Basta confrontar os modelos atuais de aparelhos de ar condicionado, dos próprios telefones móveis, de computadores, de carros, etc. Um exemplo bem significativo, no campo da saúde, é a encefalopatia traumática crônica, que parece ter sido responsável pela morte prematura do capitão da seleção brasileira de futebol, na copa de 1958, Luís Bellini. O estudo pioneiro sobre a enfermidade relacionada a concussões (golpes na cabeça e que causam interrupção temporária das atividades cerebrais) repetitivas no cérebro, sobretudo, de ex-jogadores, data de 1928, quando da divulgação de artigo no Journal of American Medical Association (Jama). Em 2002 e em 2008, os cientistas retomam a discussão e, hoje, 2014, a ciência ainda continua em busca de entender os mecanismos das concussões, ou seja, avança ininterruptamente.

O número de feitos memoráveis do homem é de tal dimensão e de tal forma diversificado que consulta à "velha" internet remete a uma série de sites, cujas listagens dos maiores inventos da humanidade divergem entre si. Mesmo assim, asseguram, sempre, o eterno caminhar do ser 


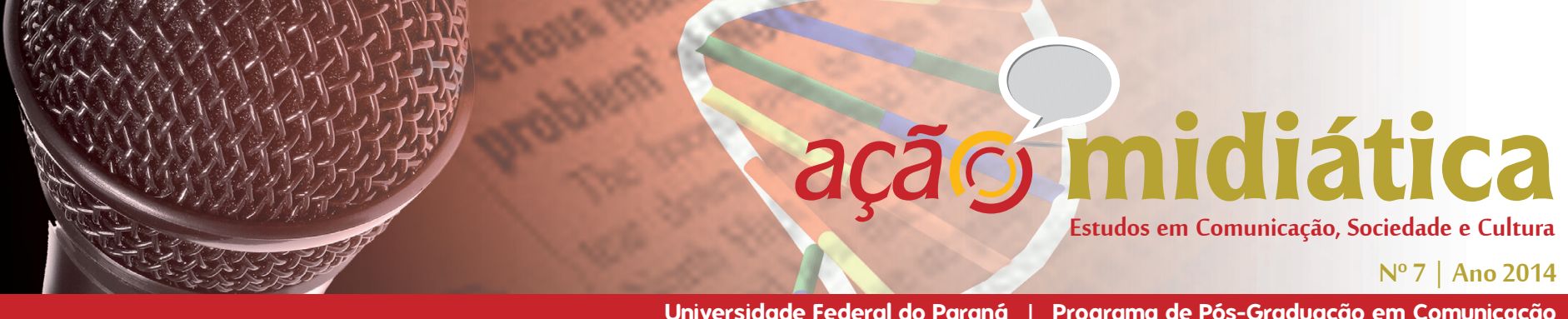

humano em busca de inovações nos mais diferentes segmentos, incluindo a medicina, a área agrícola, o meio ambiente e quaisquer outros territórios, como transportes e alimentação. Desse modo, mais do que antes, as palavras de Gomes (2014, p. 93) assumem extrema veracidade: “[...] as tecnologias eletrônicas em expansão têm ocupado o planeta, penetrando em todos os setores da vida individual e social e se incorporado aos âmbitos histórico, político, social, econômico, cultural, em especial, ao segmento educacional".

Sob essa perspectiva, é objetivo central deste artigo discutir, em uma abordagem qualitativa e descritiva, a comunicação científica além da ciência. Quer dizer, prima-se pela importância do fluxo informacional que transmuta a vida do homem contemporâneo, no momento em que extrapola os limites da comunidade científica e chega ao conhecimento das coletividades. A concepção original da comunicação científica referente à circulação do conhecimento científico no âmbito restrito da comunidade científica segue, na atualidade, rumo às populações com o fim de assegurar o retorno dos investimentos à sociedade. Tal importância é óbvia, no momento em que há o mínimo de conscientização de que ciência e tecnologia existem tão somente em função do homem, reforçando as palavras literais de Salcedo (2010, p. 21), quando diz que "[...] os produtos resultantes das práticas em C\&T são, ao mesmo tempo, as glórias e as indigências da contemporaneidade".

\section{Pesquisa e divulgação científica}

Ora, se a comunicação científica fundamenta-se na informação científica, responsável pelo conhecimento científico, o qual, por sua vez, representa acréscimo ao status quo de objetos particulares de estudo ou de especialidades ou de grandes áreas, é evidente que a pesquisa científica está no alicerce de todo o processo de comunicação científica. Consiste em elemento responsável por novos achados, advindos de trabalhos exaustivos de cientistas e pesquisadores, a quem compete não apenas a produção de novos conhecimentos, mas, também, a avaliação dos resultados advindos dos pares. É um circuito ininterrupto que se estabelece entre os pesquisadores, de tal forma que são eles, invariavelmente, consumidores de informação (para executar suas próprias pesquisas); produtores de informação (para divulgar suas próprias pesquisas); e avaliadores de informação (para validar - ou não - os achados dos demais membros da comunidade científica).

Indo além desse ciclo restrito de fluxo informacional intramuros (comunidade científica), ciente do caráter social da C\&T, é imprescindível divulgar resultados. Targino (2011), ao longo dos anos, tem insistido na ideia elementar de que pesquisa científica e divulgação de achados são atividades indissociáveis, no sentido de que qualquer investigação de natureza científica só se consolida quando os dados obtidos são devidamente divulgados. Em outras palavras, ao pesquisador não compete apenas executar planos de investigação 


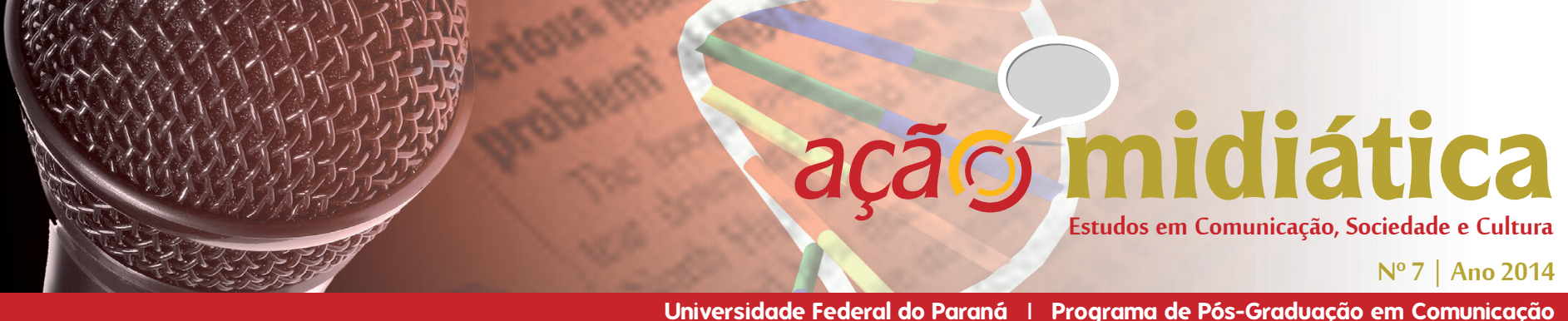

científica, mas, sim, combater o analfabetismo científico (impossibilidade de acesso ou dificuldade de assimilar as informações e os conhecimentos disponíveis), que alcança povos desenvolvidos, em desenvolvimento e terceiro-mundistas. Aliás, é preciso reiterar que a alfabetização científica incorpora três elementos: (1) noção geral sobre certos conceitos e temas básicos da ciência; (2) noção sobre a essência da atividade científica, (3) noção sobre a função social da C\&T. É então que surpreendem os dados coletados pelo autor Isaac Epstein, em seu dicionário "Divulgação científica: 96 verbetes". Em uma das maiores potências mundiais, ou seja, nos Estados Unidos da América, apenas 6\% da população é considerada alfabetizada cientificamente, embora, no meio acadêmico, tal índice suba para $17 \%$ :

[...] $63 \%$ dos americanos adultos não têm consciência de que os dinossauros desapareceram muito antes do aparecimento do homem, de que os antibióticos matam as bactérias, mas não os vírus e $57 \%$ não sabem que o elétron é menor do que o átomo [...]. Metade da população norte-americana não sabe que a Terra gira em torno do sol e que cada volta dura um ano [...] (EPSTEIN, 2002, p. 11).

Em termos de Brasil, ao tempo em que faltam estatísticas confiáveis sobre o analfabetismo científico, há consenso de que a situação é grave. A prova evidente é o resultado do Programa Internacional de Avaliação de Estudantes (PISA), ano 2012, em que os estudantes brasileiros ocupam o 59. ${ }^{\circ}$ lugar em ciências em uma listagem de 65 países, o que representa o pior desempenho em relação às demais áreas, como matemática e português. A esse respeito, eis o que diz trecho publicado no "Jornal da Ciência" da credível Sociedade Brasileira para o Progresso da Ciência:

[...] a população brasileira não conhece os seus próprios cientistas e, muito menos, a ciência e tecnologia aqui produzidas [...] A maioria dos entrevistados não frequenta espaços científicos e culturais, como museus, zoológicos, jardim botânicos e bibliotecas.

Para [...] reverter essa vergonhosa posição no PISA é preciso que haja uma inflexão da divulgação e a popularização da ciência e que o público-alvo sejam as crianças, adolescentes e adultos. "A ciência deve ser matéria diária nos vários veículos da mídia: jornais, revistas, rádio, televisão, web, etc. Essas matérias devem abordar desde a história da ciência, as grandes descobertas científicas, e mostrar a aplicação dos resultados das descobertas no cotidiano da vida de cada um [...]"

[...] A educação científica [...] pode ser perfeitamente iniciada na faixa etária de dois e três anos. Nessa idade as crianças são curiosas e, portanto, ávidas e motivadas para a iniciação científica. "[Mas], na maioria dos lares brasileiros a ciência não faz parte do cotidiano e certamente o analfabetismo científico é bem maior que o analfabetismo das letras" [...] (FERREIRA, 2013, não paginado). 
Diante de tal constatação, visando ao amplo alcance de pesquisas executadas, entra em cena uma série de estratégias. A comunicação científica inclui estágios distintos com particularidades também distintas, mas que se inter-relacionam sistematicamente. Trata-se de aporte teórico exaustivamente estudado e discutido por clássicos da comunicação científica, a exemplo de William D. Garvey; Belver C. Griffith; Yves-François Le Coadic; Arthur Jack Meadows; Derek de Solla Price; John Ziman, entre muitos outros. Para evitar a repetição de noções já devidamente disseminadas, de forma concisa, acrescenta-se que esses estágios favorecem a gradação do sistema informal para o formal, perpassando pelo semiformal até alcançar a comunicação superformal e, decerto, a comunicação eletrônica. No entanto, as formas de comunicação não são excludentes. Isto é, uma mesma pesquisa pode ser veiculada tanto por meios informais (conversas, telefonemas, cartas, visitas in loco a institutos de pesquisa) quanto semiformais, caso clássico dos anais ou das comunicações de eventos científicos.

No caso da comunicação informal, prevalece a oralidade e os contatos interpessoais são isentos de qualquer formalismo, o que justifica a denominação popular de comunicação oral. Em se tratando da comunicação semiformal, simultaneamente, conserva traços informais em sua apresentação oral e discussões daí advindas, mas, também, traços formais em sua divulgação por meio de cópias ou edições. Além das comunicações em encontros científicos, editadas ou não, podem ser aqui categorizadas as pré-edições (preprints); as versões provisórias (prepapers); as cartas aos editores comunicando pesquisas em andamento (letters) e outros gêneros de publicação, haja vista que essas categorizações não são rígidas, tampouco universais.

As pesquisas podem estar diluídas, ainda, em livros, periódicos, obras de referência em geral, relatórios técnicos, ou seja, os chamados meios formais, que primam pelo registro escrito e, assim sendo, estão impregnados pelo formalismo, a exemplo do citado artigo do Jama. A transição da comunicação formal para a comunicação científica superformal se dá graças a filtros de qualidade. Referem-se a publicações resultantes de serviços de indexação e resumos, tais como bibliografias de bibliografias e abstracts ou obras específicas de revisões de literatura, como o título Annual Review of Information Science and Technology (https://www.asis.org/ Publications/ARIST), obra renomada no domínio da ciência da informação.

E mais, há a perspectiva revolucionária da comunicação eletrônica, que incorpora a manutenção de portais, sites, blogs e outros dispositivos, como celular, smartphone e tablet. De fato, a comunicação eletrônica caminha pari passu com qualquer um dos meios "tradicionais", ou seja, um livro, mesmo em sua faceta de comunicação formal e estruturada, pode ser veiculado como e-book, tal como se dá com artigos de periódicos, comunicações de congresso, preprints, prepapers, letters e quaisquer outros itens. Até as conversas, reconhecidamente informais ("palavras são palavras, nada mais que palavras"...) ganham sua versão eletrônica, com os populares chats e uma série de outros recursos interativos, salientando a força das inovações 
tecnológicas em prol do processo desenvolvimentista das nações, quando C\&T figuram como elementos básicos para acelerar o circuito informacional e solucionar questões de ordem social.

Em outras palavras, face às diferentes inovações tecnológicas, a disseminação de notícias é mais ágil e veloz. Em poucos segundos, há a chance de compartilhamento, divulgação e obtenção de informações advindas de qualquer local geográfico e de qualquer instância. E esse fenômeno não se limita aos poderosos conglomerados de comunicação. Além de grandes jornais, poderosos sistemas de televisão e de rádio, portais e sites consolidados, a circulação imediata ou em tempo real de dados/informações/conhecimentos é possível na esfera de veículos de comunicação de pequeno porte. Basta que incorporem a globalização em sua filosofia de trabalho e noticiem o que ocorre mundo afora, sem relegar elementos nacionais, regionais e locais em busca da efetivação da glocalização (globalização + localização), que diz respeito à presença da dimensão local na produção de uma cultura global.

Entretanto, a facilidade de circulação de informações nem sempre é sinônimo de divulgação científica. A delimitação do que é ou não científico está irremediavelmente sujeita a complexo julgamento de valores. Na internet, após a imprescindível divulgação dos textos, os critérios de cientificidade (coerência, consistência, originalidade, objetividade e submissão à avaliação dos pares) são ainda mais discutíveis. As tecnologias favorecem, sim, a ampliação de número de publicações, mas é imprescindível rechaçar a postura simplista e equivocada: mais textos, mais ciência. É como acreditar que a informatização per se opera milagres, em vez de pensar no uso do computador e demais apetrechos tecnológicos como meros instrumentos capazes de imprimir maior agilidade, rapidez e eficiência aos procedimentos.

Significativo arquétipo é a blogosfera. Com temáticas diversificadas, os blogs, ao longo dos anos, estão se posicionando como poderosa ferramenta de comunicação na esfera virtual. No entanto, conceitos e elementos comunicacionais na blogosfera se tornam cada vez mais intrigantes e discutíveis, tornando o já indefinido campo da comunicação um caos ainda maior (SANTOS, 2013). A evidência está em diferentes pesquisas, como a empreendida por Caregnato e Sousa (2010). Com base em referenciais teóricos consolidados, os autores discutem o papel dos blogs científicos brasileiros e a configuração das redes de links por eles constituídas. Dentre as inferências advindas da análise de 23 blogs, chama atenção a mescla de resultados positivos e negativos. Exemplificando: a apropriação da blogosfera como instrumento de comunicação científica advém do esforço de indivíduos não necessariamente vinculados à academia, tal como comprovado por Renata Silva dos Santos. Ou seja, ambas as pesquisas apontam elevado número de blogs sob a responsabilidade de cidadãos comuns, em proporção mais elevada do que cientistas, pesquisadores, acadêmicos e jornalistas. São fortes indícios do interesse da sociedade em geral pela C\&T, em um sopro de otimismo frente ao risco do analfabetismo científico. 
Porém, do outro lado, Caregnato e Sousa (2010, p. 72) atestam que os blogs sobre temas científicos ainda são, majoritariamente, escritos de forma individual. Além do mais, registram significativa presença de blogs isolados, ou seja, sem links. O insignificante número de comentários permite deduzir que "os blogs de [...] pesquisadores estão sendo mais utilizados como repositórios de informação e a partir de perspectiva meramente informativa do que como espaço de interação entre os estudiosos". Tal constatação contraria tanto as práticas comunicacionais típicas da cibercultura (interatividade é elemento básico) quanto os princípios fundamentais da comunidade científica, responsável pela evolução da C\&T.

Afinal, é graças ao contato permanente com os pares e, portanto, no microcosmo da comunidade científica, que o reconhecimento científico do pesquisador acontece. Somente posteriormente, e se for o caso, alcança prestígio social mais amplo. Decerto, a matériaprima do cientista conduz às contribuições de seus predecessores, uma vez que qualquer novo conhecimento parte de saberes preexistentes, o que justifica a afirmativa de Ziman (1979, p. 117, tradução nossa), para quem, os trabalhos científicos “[...] são elaborados por processo que lembra o de coser ou a maneira de acomodar as peças de um quebra-cabeça, ligando-se umas às outras". Cada texto científico se assemelha a "[...] uma família humana, exceto pelo fato de que, em vez de serem necessários dois pais para produzir um filho, são necessários cerca de 12 pais diversos", os quais se movem como em uma sociedade permissiva, produzindo, graças a combinações distintas, cerca de um filho a cada ano.

Isto é, hoje, não deveria ser possível encontrar produções científicas isoladas ou individualizadas, em blogs ou em qualquer outro suporte. Mais do que antes, as comunidades científicas possuem aspirações bem definidas, em que há visível sistema de trocas. O pesquisador repassa à comunidade informações que detém e os novos conhecimentos gerados. Em troca, recebe sua confirmação como cientista. Esta alcança dois níveis. De início, o reconhecimento dos pares, e, posteriormente, a confirmação institucional, que exige produção intensa de publicações originais.

Aliás, esse tópico também requer cuidados extremos alusivos à tendência de produção intelectual exacerbada e desatenta aos princípios de cientificidade. Sobrevivem duas correntes de pensamento antagônicas representadas por ideias contidas em dois manifestos relativamente recentes - embora a discussão seja bastante antiga e remonte à prática do lema - publish or perish. Intitulado "The slow science manifesto", o primeiro documento denuncia os malefícios da produção desenfreada semelhante a uma "indústria de papéis" inútil, desnecessária e estéril. O segundo, "The 'slow science 'movement must be crushed!" critica, com ironia, o primeiro e finaliza afirmando: "Temo que se os cientistas realmente desacelerarem e começarem a publicar apenas dados de alta qualidade e teorias cuidadosamente checadas, não terei muita coisa mais a escrever" (p. 2). Resta, pois, a cada pesquisador manter o bom senso no sentido de investir na 


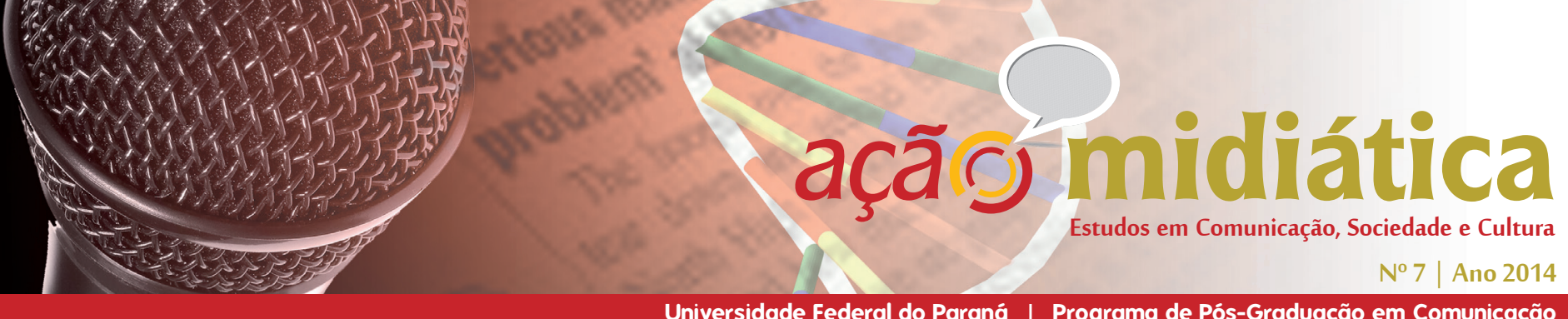

comunicação científica nos limites da esfera científica e, sobretudo, no âmago da sociedade para cumprir a função mor da ciência - a melhor qualidade de vida do ser humano - sem desrespeitar a integridade na pesquisa e na publicação científica (COURY, 2012; SHINKAI, 2011).

\section{Divulgação científica/modalidades ou terminologias}

Retomando-se a relevância da comunicação científica e de sua inserção na tessitura social, é preciso reafirmar a diversidade de modalidades ou de terminologias, descrita por Portela (2014). Autores brasileiros de reconhecido valor no universo temático em discussão, como Wilson da Costa Bueno, em diferentes publicações, estabelecem diferenciação entre os termos difusão científica, disseminação científica, divulgação científica e comunicação da ciência e da tecnologia. No entanto, apesar de tal distinção e da força crescente do jornalismo científico, a opção do presente artigo é pela expressão divulgação científica, adotada por teóricos em comunicação científica, à semelhança de Le Coadic (1998); Meadows (1991); e Ziman (1984), o que não impede o esclarecimento acerca dos termos comuns empregados ao longo da empreitada com vistas ao engajamento social da C\&T.

Difusão científica é todo e qualquer processo utilizado para comunicar a informação científica e tecnológica (ICT). É, pois, o termo mais abrangente e, também, o mais antigo, em vigor desde o século XVI, quando os primeiros cientistas burlam a censura imposta pelo Estado e pela Igreja, mantendo-se em contato com os pares em reuniões sigilosas, momento em que tomam conhecimento das novas descobertas alusivas à filosofia natural. A disseminação científica, por sua vez, diz respeito ao fluxo informacional voltado especificamente para cientistas e pesquisadores da área ou de campos afins, quando recebe, então, a denominação de disseminação intrapares. A extrapares destina-se aos especialistas de fora da área restrita de especialização. A divulgação científica dirige-se ao grande público, enquanto a expressão comunicação da ciência e da tecnologia nomeia a comunicação da ICT transcrita em códigos especializados e direcionados a uma audiência seleta de especialistas.

Em se tratando, especificamente, do jornalismo científico, para Portela (2014, não paginado), o importante é a compreensão de que a ICT, sob a forma de notícia científica,

[...] precisa estar cada vez mais presente nos meios de comunicação, refletindo as demandas informacionais do homem contemporâneo, pois é ela que possibilita ao indivíduo estar informado e consciente acerca do papel evolutivo da ciência. É a confirmação da democratização da informação como ideal a ser perseguido.

Como previsto por Ferreira (2013), em transcrição literal anterior, vivencia-se a consolidação gradativa do jornalismo científico, comprometido com a função de divulgar a ciência. É o jornalismo assumindo inter-relação estreita e contínua com a ciência, a fim de 
intensificar a divulgação de informações relativas à C\&T, em linguagem acessível ao grande público. Isto significa dizer que, independentemente da terminologia utilizada, todos os esforços são válidos quando a proposta é romper a apatia da população, haja vista que o desinteresse e o desconhecimento do povo brasileiro em relação à ciência e à tecnologia são fatores impeditivos do processo desenvolvimentista do país, como Epstein (2002) alerta, com veemência.

\section{Palavras finais}

É evidente que a consecução da meta governamental e das instituições de pesquisa, dentre as quais estão faculdades, centros universitários e universidades, no sentido de combater o analfabetismo científico e, por conseguinte, assegurar a prática da comunicação científica além dos altos muros da ciência, requer uma série de medidas. Estas devem se iniciar desde o ensino fundamental e médio perpassando pelo ambiente familiar propício à educação científica.

Se, como antes discutido, ciência e tecnologia determinam a evolução da humanidade, é preciso, desde cedo, possibilitar aos cidadãos-mirins (ou não) habilidades para que possam desvendar o universo da ciência. A inacessibilidade aos novos conhecimentos ou a incapacidade de compreendê-los cerceia a prática cidadã. A inaptidão em exercitar a análise crítica do que se passa ao seu redor conduz à marginalização do indivíduo, haja vista que C\&T, em sua condição de objeto cultural, também se impõem como forma de instituição de "[...] significados e de produção, controle e distribuição social de bens simbólicos" (SALCEDO, 2010, p. 24).

Distante de qualquer "receituário" - cada coletividade deve definir os caminhos mais adequados à sua realidade - há algumas medidas que, na prática, são universais. Além de maior cuidado com a formulação das grades curriculares, em qualquer nível de ensino, visando à incorporação de temas que permitam ao educando visualizar o mundo de forma abrangente, sem, no entanto, relegar os interesses individuais significativos para sua própria vida, há uma série de iniciativas possíveis. Entre elas: adoção de programas de ensino da ciência desde a educação fundamental; investimentos contínuos nas chamadas feiras de ciências, com suas diversificações, tais como concursos, gincanas e medidas similares, sempre com a intenção implícita e explícita de estimular criticidade, criatividade e curiosidade intelectual com vistas a um comprometimento social crescente, contínuo e sistemático.

Além do mais, vale a pena lembrar, como o fazem os já citados clássicos da comunicação científica, Garvey (1979); Griffith (1989); Le Coadic (1998); Meadows (1991); Price (1976); Ziman (1984), além de estudiosos brasileiros, como Epstein (2002), que a educação científica ou alfabetização científica prevê o domínio das inovações tecnológicas. Isso porque as tecnologias de informação e de comunicação, além de permitirem a inclusão digital, concorrem para a divulgação da ciência além das fronteiras da comunidade científica, e, consequentemente, para a apreensão de novos conteúdos incorporados ao cotidiano do homem contemporâneo: 
